\title{
NEW RECORDS OF RARE GENERA OF THE SUBFAMILY Cheloninae (Hymenoptera: Braconidae), WITH DESCRIPTION OF TWO NEW SPECIES FROM VIETNAM
}

\author{
Khuat Dang Long ${ }^{1, *}$, Nguyen Van Dzuong ${ }^{2,3}$, Dang Thi Hoa ${ }^{1}$ \\ ${ }^{1}$ Institute of Ecology and Biological Resources, VAST, Vietnam \\ ${ }^{2}$ Graduate University of Science and Technology, VAST, Vietnam \\ ${ }^{3}$ Tay Bac University, Son La, Vietnam
}

Received 19 April 2019, accepted 10 July 2019

\begin{abstract}
New species of subgenus Areselonus Braet, 1999 and genus Odontosphaeropyx Cameron, 1910, viz. Chelonus (Areselonus) intermedius Long, sp. n. and Odontosphaeropyx plesius Long, sp. n. (Braconidae: Cheloninae) are described and illustrated. Additionally, these two rare taxa are newly recorded for Vietnam's braconid fauna. The checklist and distribution of the already known species of the genera are also provided.
\end{abstract}

Keywords: Ichneumonoidea, Odontosphaeropygini, distribution, parasitoids, subgenus, Afrotropical, Australasian, Oriental, Vietnam.

Citation: Khuat Dang Long, Nguyen Van Dzuong, Dang Thi Hoa, 2019. New records of rare genera of the subfamily Cheloninae (Hymenoptera: Braconidae), with description of two new species from Vietnam. Academia Journal of Biology, 41(3): 1-9. https://doi.org/10.15625/2615-9023/v41n3.13884.

"Corresponding author email: khuatdanglong@gmail.com

(C2019 Vietnam Academy of Science and Technology (VAST) 


\section{INTRODUCTION}

Little is known of the Braconidae from Vietnam generally and its subfamilies so far, and Chelonidae is no exception. Two previous papers published by Long \& Belokobylskij (2003) and Long \& van Achterberg (2014) in the period 2004-2014 provided lists of the 492 braconid species belonging to 24 subfamilies of the family Braconidae from Vietnam, but in these papers, only four species of the subfamily Cheloninae were recorded. These two works have given an indication that many species from Vietnam's are waiting to be recognized and described. Actually, since 2014 dozens of Vietnamese braconid wasps were recorded and described as new species (Khuat Dang Long, 2017).

Cheloninae Förster, 1862 s.s. is the cosmopolitian subfamily with more than 1,500 valid taxa ( $\mathrm{Yu}$ et al., 2005), their representatives are reported as parasitoids of insects belonging to various families, such as Noctuidae, Geometridae, Tortricidae, Pyralidae, and Gelechiidae (van Achterberg, 1990; Shaw \& Huddleston, 1991). Of genera of the Cheloninae, the subgenus Areselonus Braet, 1999 is a rather rarely collected among the genus Chelonus, and up to now two species were known from the Oriental and two from Australasian regions ( $\mathrm{Yu}$ et al., 2016; Ahmad \& Ghramh, 2018).

Among the monotypic tribe Odontosphaeropygini Zettel 1990, the genus Odontosphaeropyx Cameron is a rare genus of the chelonine braconids, that was named by Cameron in 1910 (Type-species: Odontosphaeropyx ruficeps Cameron, 1910). Up to date, of nine included species in Odontosphaeropyx Cameron, eight species were described from the Afrotropical region (Kittel et al., 2016; Yu et al., 2016), and recently one species was recorded and described from Oriental region (Quicke \& Butcher, 2018). Eight Odontosphaeropyx species from the Afrotropical region were keyed and illustrated by Braet et al. (2014) without any information of hosts.

In this paper we aim to report the discovery of one new species of subgenus
Areselonus and one new species of Odontosphaeropyx from Vietnam, and additionally, the subgenus Areselonus and the genus Odontosphaeropyx are recorded for the first time for the braconid fauna of Vietnam.

\section{MATERIALS AND METHODS}

This study is based on specimens deposited in the Parasitic Hymenoptera Collections at the Institute of Ecology and Biological Resources (IEBR), Vietnam Academy of Science and Technology (VAST), Ha Noi, Vietnam. For several years the authors has been collecting Braconidae from all over Vietnam to gain an understanding of the braconid fauna of Vietnam. In this paper part of the discoveries are described.

Terminology used in this paper follows van Achterberg (1993), sculpture terms are based on Harris (1979), refering Sharkey \& Wharton (1997) and vein terminology follows the modified Comstock-Needham system (van Achterberg 1993). For identification of the subfamilies, see van Achterberg (1993); for the identification of tribes and genera of the subfamily Cheloninae, see Zettel (1990); for additional references and data, see $\mathrm{Yu}$ et al. (2016). For virtually all species we used an Olympus ${ }^{\circledR}$ SZ61 binocular microscope; key to species and description of species are based on female; measurement were carried out using an Olympus ${ }^{\circledR}$ SZ40 binocular microscope; the photographs were made with Sony ${ }^{\circledR} 5000$ digital camera attached to a Nikon ${ }^{\circledR}$ SMZ $800 \mathrm{~N}$ binocular microscope connected to a PC at IEBR. The scale-lines of the plates indicate in $\mathrm{mm}$. Abbreviations used in this paper are as follows: $\mathrm{POL}=$ postocellar line; $\mathrm{OOL}=$ ocularocellar line; $\mathrm{OD}=$ diameter of posterior ocellus; MT: Malaise trap; 'Chelo.+number': code number indexing for specimens of the Cheloninae in the collection at IEBR. C: Central, NE: Northeastern, NP: National Park.

\section{RESULTS}

\section{SYSTEMATICS}

Checklist and distribution of Chelonus, subgenus Areselonus species

Chelonus (Areselonus) chailini Walker \& Huddleston, 1987/Oriental: Malaysia. 
Chelonus (Areselonus) intermedius Long, sp. n./Oriental: Vietnam.

Chelonus (Areselonus) minutissimus Braet, 1999/Australasian: Papua New Guinea.

Chelonus (Areselonus) missai Braet, 1999/Australasian: Papua New Guinea.

Chelonus (Areselonus) spinigaster Ahmad \& Ghramh, 2018/Oriental: India.

\section{Checklist and distribution of Odontosphaeropyx species}

Odontosphaeropyx bicoloratus Braet, 2014/Afrotropical: Namibia, Tanzania.

Odontosphaeropyx flavifasciatus (Zettel, 1990)/Afrotropical: Democratic Republic of Congo, Nigeria. (=Pachychelonus flavofasciatus Zettel).

Odontosphaeropyx fulviventris (Brues, 1924)/Afrotropical: South Africa, Zimbabwe.

Odontosphaeropyx gracilis Braet, 2012/ Afrotropical: Madagascar.

Odontosphaeropyx leucocoxus Braet, 2012/Afrotropical: Madagascar.

Odontosphaeropyx matasi Quicke \& Butcher, 2018/Oriental: Thailand.

Odontosphaeropyx maximus (Zettel, 2002)/Afrotropical: Kenya.

Odontosphaeropyx mkomaziensis Kittel, 2014/Afrotropical: Tanzania.

Odontosphaeropyx plesius Long, sp. n./Oriental: Vietnam.

Odontosphaeropyx ruficeps Cameron, 1910/Afrotropical: South Africa.

\section{DESCRIPTION OF SPECIES}

Chelonus (Areselonus) intermedius Long, sp. n. (Figs 1-10)

MATERIAL. Holotype, o "Chelo.094" (IEBR), NE Vietnam: Vinh Phuc, Tam Dao NP, forest, MT. 04-14.iv.2001, KD Long.

Female, body length $2.3 \mathrm{~mm}$, fore wing length $1.7 \mathrm{~mm}$, antenna $1.3 \mathrm{~mm}$ (Fig. 1).

Head. Antenna with 16 segments; antennal socket inserted close to top of eye; scapus robust, $3.25 \times$ as long as wide (13:4); third antennal segement $1.2 \times$ as long as fourth segment (7:6); penultimate antennal segement as long as wide, near quadrate; $0.6 \times$ as long as apical segment (2.5:4); antennal segements with placodes on all sides; in dorsal view, head $2.5 \times$ as high as broad (32:13); eye length $1.6 \times$ temple (8:5) (Fig. 3); POL : OD : OOL $=6: 2: 6$; in lateral view, eye $1.6 \times$ as high as broad (13:8); transverse width of eye as long as temple (8:8); in frontal view, face width $2.4 \times$ length of face and clypeus combined (19:8); maxillary palpus $0.45 \times$ length of head (10:22); clypeus in flattened lateral view, with slightly convex ventral margin, without apical teeth, coriaceous (Fig. 2); basal width of mandible malar space $0.4 \times$ as long as distance from mandible to eye margin (3:7); malar space $0.6 \times$ as long as eye height (7:12); distance between tentorial pits $1.3 \times$ as long as distance fromp pit to eye margin (8:6). Face finely transversely rugose; clypeus coriaceous medially, finely transversely rugose laterally; frons with longitudinal rugosities with carina between antennal sockets; vertex rugose; occiput transversely rugose; temple longitudinally striate; occipital carina complete, evenly cocave, running close to base of mandible.

Mesosoma. Pronotal side rugose; mesoscutum distal protruding above pronotum; in lateral view, mesonotum $1.6 \times$ as long as height (41:26); in dorsal view, mesoscutum $0.9 \times$ as long as head width (30:32); mesoscutum rather flat, foveate rugulose (Fig. 4); notauli faintly indicatated; scutellar sulcus straight, with 4 carinae, $0.4 \times$ as long scutellum (3:8); scutellum rugose; mesopleuron foveate-rugulose; precoxal sulcus absent (Fig. 10); metapleuron foveaterugulose; propodeum with four pointed tubercles; anterior area of propodeum areolate-rugose; posterior area behind tubercles steep, foveate-rugulose.

Wings: Length of fore wing $2.8 \times$ as long as its maximum width (70:25); pterostigma swollen, length of pterostigma $2.0 \times$ as long as its width (16:8), and $1.1 \times$ as long as vein 1 R1 (16:15); vein SR1 sclerotized in basal 0.22 of vein (4:18) (Fig. 5); vein $r$ arising behind 
middle of pterostigma, $0.8 \times$ vein 3 -SR (3:4), and $0.6 \times$ as long as vein 2-SR (3:5); 1 CU1:cu-a:2-CU1 (2:4:9); vein 1-M 2.25 $\times$ vein $\mathrm{m}$-cu (9:4); vein m-cu antefurcal. Length of hind wing $3.5 \times$ as long as its maximum width (59:17); vein 2r-m almost perpendicular with vein $2-\mathrm{SC}+\mathrm{R}$ (Fig. 6) vein M+CU $1.2 \times$ as long as vein $1-\mathrm{M}(11: 9)$, vein $1-\mathrm{M} 4.5 \times$ as long as vein $1 \mathrm{r}-\mathrm{m}(9: 2)$.

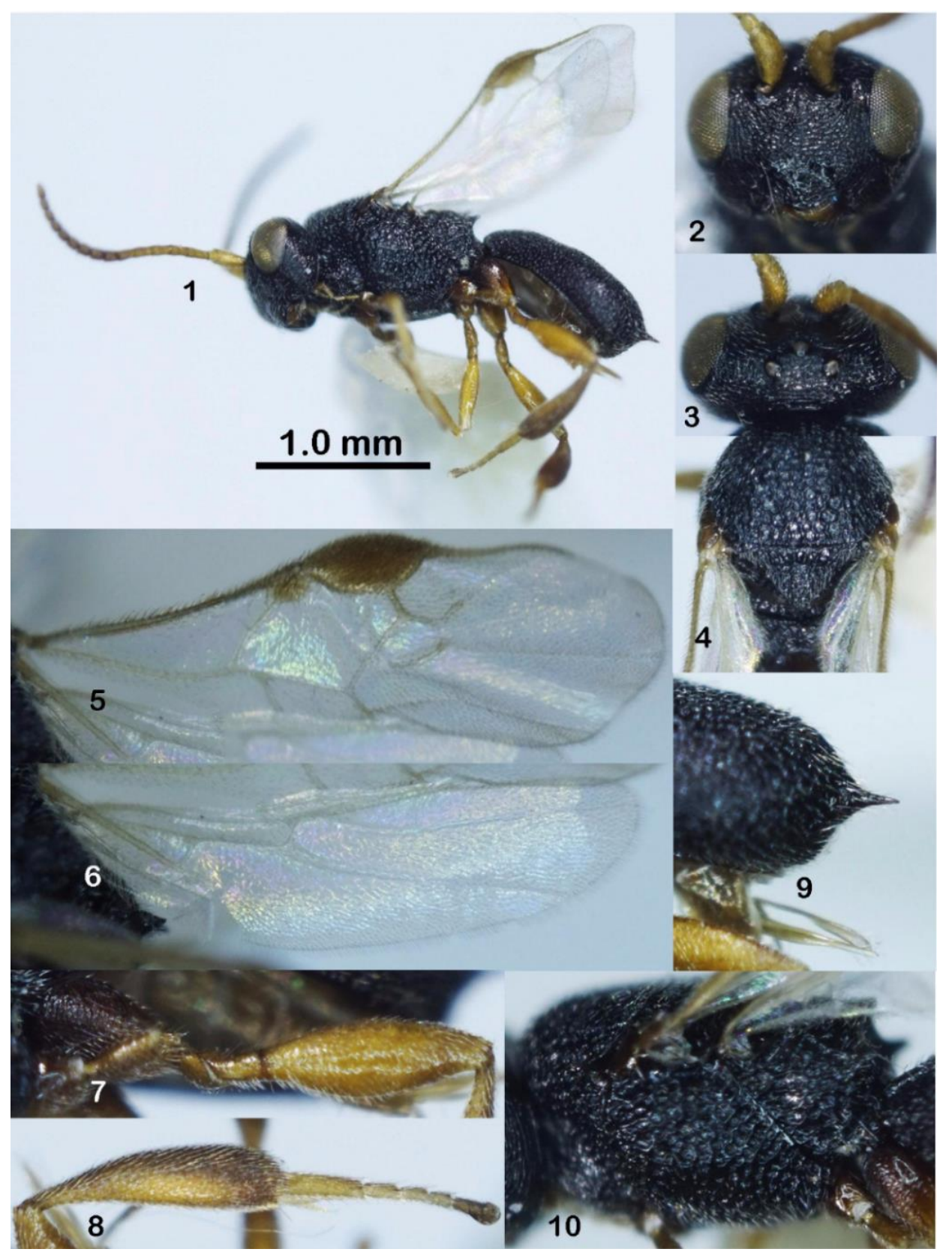

Figures 1-10. Chelonus (Areselonus) intermedius Long, sp. n., Holotype, female: 1. Habitus; 2. Head, frontal view; 3. Head, dorsal view; 4. Mesonotum; 5. Fore wing; 6. Hind wing; 7. Hind coxa and femur, lateral view; 8 . Hind tibia and tarsus, lateral view; 9. Apex of carapace and spine, lateral view; 10. Mesopleuron 
Legs: Fore tarsus $1.2 \times$ as long as fore tibia (17:14); hind coxa and femur rugopunctate (Fig. 7); hind femur with short and sparse setae; hind femur, tibia and basitarsus 2.7, 4.2 and $3.5 \times$ as long as their maximum width, respectively; hind basitarsus $0.8 \times$ as long as hind tibia (19:25); hind tibia swoolen apically (Fig. 8), with oblique setae, setae on its apex longer; inner hind tibial spur long, 0.7 $x$ as long as hind basitarsus (5:7); length of hind basitarsus $0.5 \times$ length of second-fifth tarsus (7:13).

Metasoma. In dorsal view, carapace $1.7 \times$ as long as wide (43:25); in lateral view, carapace $2.6 \times$ as long as high (42:16); carapace anteriorly foveate-rugulose, posteriorly foveate-recticulate; ovipositor sheath with pointed apical spine, entirely setose and without pores apically (Fig. 9).

Color. Body black; scapus, and flagellum basally pale yellow, except apex of flagellum brownish yellow; palpi; all legs yellow; wings hyaline; pterostigma and vein 1-R1 yellow; ovipositor sheath pale yellow.

\section{Male. Unknown.}

Host. Unknown.

Etymology. From "inter" (Latin for "between", "middle"), because the new species is intermediate between $C h$. (A.) spinigaster Ahmad \& Ghramh, from India, and $C$. (A.) chailini Walker \& Huddleston, from Malaysia.

Distribution. Vietnam (Vinh Phuc).

Remarks. Chelonus (Areselonus) intermedius Long, sp. n. is similar to both species from the Oriental region, $C h$. (A.) spinigaster Ahmad \& Ghramh, 2018, from India, and $C$. (A.) chailini Walker \& Huddleston, 1987, from Malaysia but the new species differs from the first in having: a) POL $3.0 \times$ as long as OD $(1.5 \times$ in $C h$. (A.) spinigaster); b) Vein 3-SR $1.3 \times$ as long as vein $\mathrm{r}(1.6 \times$ in $C h$. (A.) spinigaster $)$; c) Carapace metasoma slightly declivous below spine (in lateral view) (Fig. 9). The new species can be distinguished from $C$. (A.) chailini in having: a) Clypeus coriaceous medially, transversely rugose laterally (sparsely punctate in $C$. (A.) chailini); and b) Carapace metasoma more or less declivous below spine [hardly or nearly perpendicular in C. (A.) chailini].

\section{Odontosphaeropyx plesius Long, sp. n. (Figs} 11-22)

MATERIAL. q "Chelo.276" (IEBR), NE Vietnam: Tuyen Quang, Na Hang, Son Phu, forest, MT, $22^{\circ} 17^{\prime} 34$ 'N-105'28'19'E, 561 m, 15.ix.2018, KD Long. Paratype, 1 ते "Chelo.053"(IEBR), C Vietnam: Thua Thien-Hue, A Luoi, MT, 20-30.viii.2005, NQ Truong.

Female, body length $7.5 \mathrm{~mm}$, fore wing length $5.7 \mathrm{~mm}$, antenna $6.2 \mathrm{~mm}$ (Fig. 11).

Head. In dorsal view, head $1.7 \times$ as broad as height (39:23); antennal socket inserted close to top of eye; antenna with 35 (missing 8 segments); antennal socket inserted close to top of eye; scapus $2.0 \times$ as long as wide (16:8); third antennal segement $1.6 \times$ as long as fourth segment (11:7); antennal segements with 4 row of placodes on all sides; in dorsal view, occipital carina complete, evenly cocave (Fig. 18); eye length $2.0 \times$ as long as wide (12:6), $0.8 \times$ as long as temple (12:15); POL:OD:OOL=5:3:18 (Fig. 18); in lateral view, eye $1.5 \times$ as high as broad (20:13); transverse width of eye $0.7 \times$ temple $(13: 18)$ (Fig. 12); in frontal view, face width $0.9 \times$ length of face and clypeus combined (37:43); maxillary palpus $0.74 \times$ length of head (37:50); clypeus large, ventral margin of clypeus sharply pointed medilly and laterally (Fig. 17); malar space basal width of mandible malar space $0.9 \times$ as long as distance from mandible to eye margin (8:9); malar space 0.8 $\times$ as long as eye height (19:25); distance between tentorial pits $2.3 \times$ as long as distance from pit to eye margin (14:6); face and clypeus with rather long setae, densely punctate (Fig. 17); frons, vertex and temple rugose-punctate; occiput with sparse but discrete punctures.

Mesosoma. Pronotal side almost smooth ventrally, areolate-rugulose medially; mesosoma $1.8 \times$ as long as height (in lateral 
view) (63:35) (Fig. 13); in lateral view, median lobe of mesoscutum distinctly protruding anteriorly above pronotum (Figs $11,13)$; in dorsal view, median lobe of mesoscutum sparsely punctate anteriorly, almost recticulate-rugulose medioposperiorly, with posterior sinuate rugosity between carinate notauli (Fig. 19); notauli deep and wide, crenulate groove of notauli running posteriorly close scutellar sulcus; lateral lobes of mesoscutum rugo-punctate; scutellar sulcus deep, curved, with 4 carinae, and $0.3 \times$ as long as scutellum (6:19), (Fig. 19); scutellum sparsely punctate; mesopleuron finely sparsely punctate, with anterior round area surrounded by crenulate groove (Fig. 13); precoxal sulcus absent; surface of mesosternum finely sparsely punctate; surface of metapleuron areolate rugose (Fig. 13); propodeum with areola and tubercles, areolate rugose laterally.

Wings: Length of hind wing $3.1 \times$ as long as its maximum width (107:35); pterostigma $4.1 \times$ as long as wide (37:9); pterostigma 0.9 $\times$ as long as vein SR1 (37:39); vein $r$ arising in basal 1.3 of pterostigma $(21: 16)$ of pterostigma; vein $\mathrm{r} 1.2 \times$ as long as vein 3 -SR $(6: 5), 0.2 \times$ vein $\operatorname{SR} 1(6: 30)$, and $0.35 \times$ vein 2-SR (6:17) (Fig. 14); vein 1-M 3.0 vein m-cu (15:5); 1-CU1:cu-a:2-CU1 (10:7:26); vein 3CU1 $3.0 \times$ vein CU1b (9:3) (Fig. 14); length of hind wing $4.6 \times$ as long as its maximum width (88:19); vein $1-\mathrm{SC}+\mathrm{R}$ horizontal; hind wing vein $\mathrm{M}+\mathrm{CU} 0.5 \times$ as long as vein $1-\mathrm{M}$ (11:22); vein $1-\mathrm{M} 5.5 \times$ as long as vein $2 \mathrm{r}-\mathrm{m}$ (22:4) (Fig. 15); hind wing vein cu-a desclerotized

(Fig. 15); hind wing with 4 hamuli.

Legs: Fore tarsus $0.9 \times$ as long as fore tibia (45:52); hind tarsus slightly longer fore tibia (77:75); length of hind femur, tibia and basitarsus 3.6, 6.5 and $6.25 \times$ as long their maximum width; hind tarsal claws with a pectin of 3 teeth (Fig. 22); inner hind tibial spur $1.3 \times$ outer spur (12:9), and $0.3 \times$ as long as hind basitarsus (12:37); length of hind basitarsus $0.4 \times$ hind tibia (25:59), subequal to second-fifth tarsus (25:26); hind coxa almost smooth; hind femur finely punctate.
Metasoma. In dorsal view, carapace $2.7 \times$ as long as wide (96:35); sutures between three carapace segments well developed, wide, crenulate (Fig. 16); first metasomal tergite slightly shorter its apical width (30:31); dorsal carinae on basal 0.8 of tergite (24:30) (Fig. 16); median length of second tergite 0.8 $\times$ as long as basal width (41:49); first metasomal tergite areolate-rugulose medially, longitudinally rugose laterally (Fig. 16); second tergite longitudinally rugose; third tergite punctate-recticulate; in lateral view, ovipositor sheath not protruding behind apex of metasoma; in lateral view, carapace $2.7 \times$ as long as height (96:35); hypopygium sclerotized throughout, truncate apically (Fig. 21); ovipositor sheath widened apically, glabrous basally, setose apically.

Color. Tricoloured body, antenna and head black; mesosoma rufous-orange; fore coxa brownish yellow; fore tibia dark brown; fore tibia and tarsus pale yellow; middle leg blackish brown, except middle coxa pale brown; fore, middle and hind tibial spurs pale yellow; hind leg black; first and third metasomal tergites black, but first tergite of male pale yellow baso-laterally; second tergite cream-white entirely (in female), and with apical brown triangle band (in male); fore wing hyaline basally, dark brown medially and apically, with a whitish cross-band beneath parastigma running to apex of subdiscal cell; hind wing hyaline, infuscate apically; ovipositor largely yellow basally, brownish apically.

Variation. Male, paratype: body length $8.2 \mathrm{~mm}$, fore wing length $6.1 \mathrm{~mm}$, antenna $6.7 \mathrm{~mm}$; antenna with 40 segments; fore wing vein $r$ subequal to vein $3-S R$; hind wing with 3 hamuli; tarsal claws with a pectin of 4 teeth; first metasomal tergite dark brown but largely yellow baso-laterally.

\section{Host. Unknown.}

Etymology. From "plesios" (Greek for "near"), because the new species is close to $O$. matasi Quicke \& Butcher, from Thailand.

Distribution. NE Vietnam (Tuyen Quang); C Vietnam (Thua Thien-Hue). 


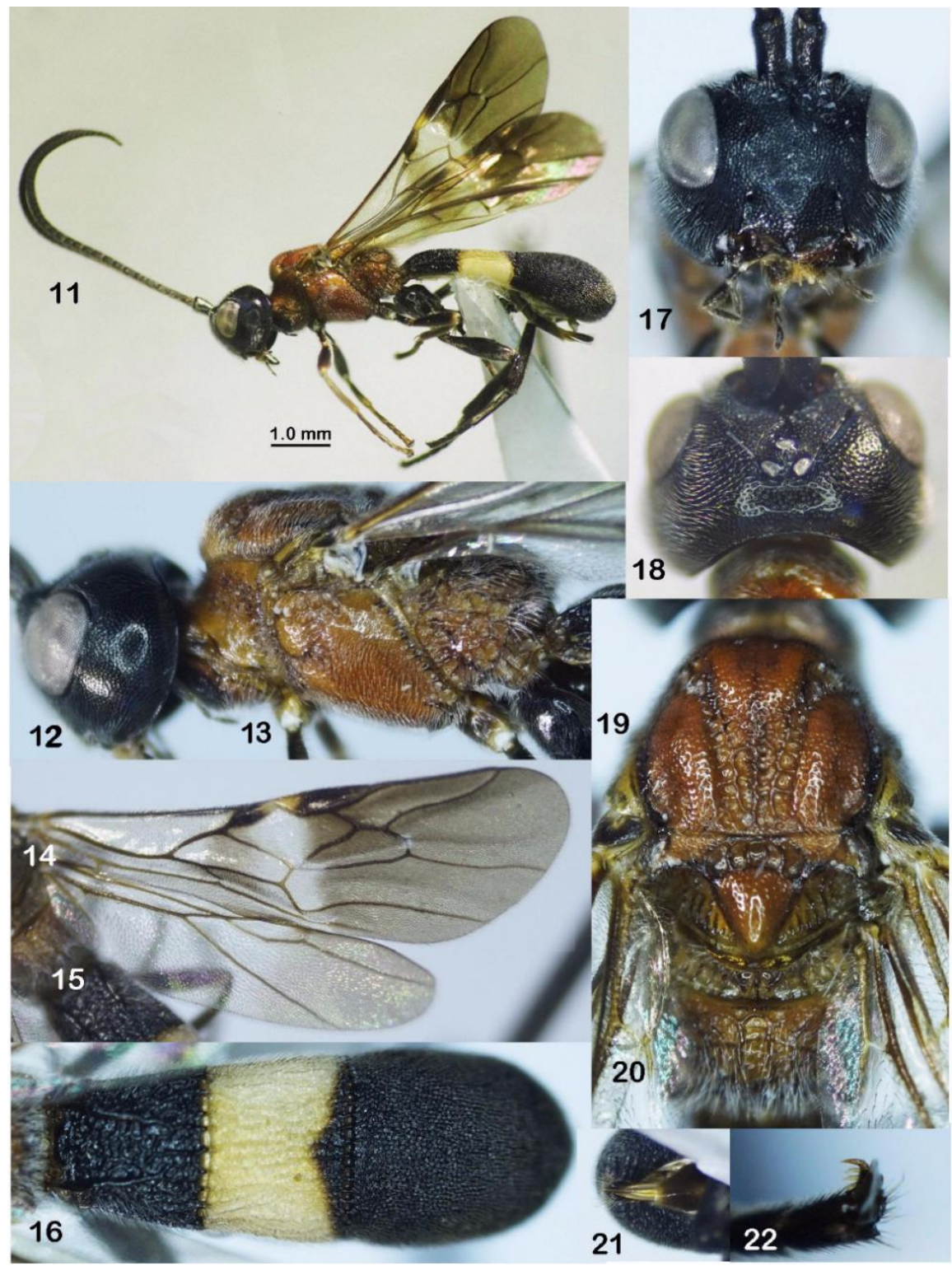

Figures 11-22. Odontosphaeropyx plesius Long, sp. n. Holotype, female: 11. Habitus; 12. Head (lateral view); 13. Mesopleuron; 14. Fore wing; 15. Hind wing; 16. Carapac, dorsal view;

17. Head, frontal view; 18. Head, dorsal view; 19. Mesonotum; 20. Propodeum; 21. Hypopigium, ventral view; 22. Outer hind tarsal claw

Remarks. O. plesius Long, sp. n. differs from all already known Odontosphaeropyx species from the Afrotropical region in having the combination of an orange thorax; a largely black metasoma with a large cream-white band in second metasomal tergite, the new species is similar to $O$. matasi Quicke \& Butcher, 2018, from Thailand, but distinctly differs from the latter by having: a) Head and mesosoma with sparse setae (O. matasi with dense setae); b) Occipital carina evenly concave (deeply concave in $O$. matasi); c) Hind tarsal claw with a pectin of 4 teeth in male (paratype) and of 3 teeth in female (holotype) (2 teeth in male $O$. matasi); d) Vein 3-SR of fore wing shorter than vein $r$ (in 
female, holotype) or subequal (in male, paratype); and e) Vein 2-SC+R of hind wing horizontal (perpendicular in $O$. matasi). $O$. plesius Long, sp. n. is also close to $O$. flavifasciatus (Zettel, 1990), from Nigeria and D.R. of Congo, but it can be distinguished from the latter in having: a) Mesopleuron sparsely punctate; b) Fore wing vein $1 \mathrm{CUb}$ $3.0 \times$ longer than vein $1 \mathrm{CUa}$; and c) Hind coxa black.

\section{DISCUSSION}

Actually, the real obstracle to discover new species of "rare genera" of the family Braconidae is the greater difficulty of collecting materials. The further extensive surveys in the remained tropical forests by different methods, e.g. malaise traps, light trap, sweep netting or pertaining rearing from the potential hosts infested on plants certainly allow to increase the numbers of specimens of "rare" taxa.

Acknowledgements: This research is funded by the Vietnam Academy of Science and Technology, under Grant for senior researchers, No. NVCC09.03/19-19. Thanks are due to Dr Nguyen Quang Truong (IEBR) for providing the specimen.

\section{REFERENCES}

Ahmad Z., Ghramh H. A., 2018. A new species of Chelonus (Areselonus) (Hymenoptera, Braconidae) from India reared from Acrocercops lysibathra (Meyrick) on Cordia latifolia Roxb. ZooKeys, 737: 75-80. https://doi.org/ 10.3897/zookeys.737.20835.

Braet Y., 1999. Description of new Braconidae (Hymenoptera) from Papua New Guinea. Belgian Journal of Entomology, 1(1): 3-20.

Braet Y., Rouse P., Sharkey M., 2012. New data on African Cheloninae (Hymenoptera, Braconidae) show a strong biogeographic signal for taxa with spined propodea. Zootaxa, 3385: 1-32.

Braet Y., van Noort S., Kittel R. N., 2014. New species of the 'rare' genera Dentigaster Zettel, 1990 and
Odontosphaeropyx Cameron, 1910 (Hymenoptera: Braconidae: Cheloninae). Austral Entomology, 54: 197-209. https://doi.org/10.1111/aen.12112.

Harris R. A., 1979. A glossary of surface sculpturing. Occasional Papers in Entomology, California Department of Food and Agriculture, 28, 1-33.

Khuat Dang Long, 2017. Dong vat chi Viet Nam (Fauna of Vietnam), Insecta: Braconidae: Alysiinae, Aphidinae, Betylobraconinae, Brachistinae, Doryctinae, Euphorinae, Exothecinae, Microgastrinae and Rogadinae. Publishing House for Science and Technology, vol. 27, 698 pp. (in Vietnamese with English summary).

Long K. D., Belokobyskij S. A., 2003. A preliminary list of the Braconidae (Hymenoptera) of Vietnam. Russian Entomogical Journal, 12(4), 385-398.

Long K. D., van Achterberg C., 2014. An additional list with new records of Braconid wasps of the family Braconidae (Hymenoptera) from Vietnam. Tap chi Sinh hoc (Journal of Biology), 36(4), 397$415 . \quad$ https://doi.org/10.15625/08667160/v36n4.5979.

Quicke D. L. J., Butcher B. A., 2018. First record of Odontosphaeropyx Cameron, 1910 from the Oriental Region with description of a new species from Thailand (Hymenoptera, Braconidae, Cheloninae). ZooKeys 809: 41-47. https://doi.org/10.3897/zookeys.809.30742.

Sharkey M. J., Wharton R. A., 1997. Morphology and terminology. In: Wharton RA, Marsh PM, Sharkey MJ (Eds) Identification manual to the New World genera of Braconidae. Special Publication of the International Society of Hymenopterists 1: 19-37.

Shaw M. R., Huddleston T., 1991. Classification and biology of Braconid wasps (Hymenoptera: Braconidae). Handbooks for the Identification of British Insects, 7(11), $126 \mathrm{pp}$. 
van Achterberg C., 1990. Revision of the western Palaearctic Phanerotomini (Hymenoptera: Braconidae). Zoologische Verhandelingen, 255, 1-106.

van Achterberg C., 1993. Illustrated key to the subfamilies of the Braconidae (Hymenoptera: Ichneumonoidea). Zoologische Verhandelingen Leiden, 83: $1-189$.

Walker A. K., Huddleston T., 1987. Chelonus chailini sp. n. (Hymenoptera: Braconidae) from Malaysia, parasitizing gracillariid moth (Lepidoptera). Bulletin of Entomological Research, 77(3): 437-440. https://doi.org/10.1017/S00074853000119 13.

Yu D. S., van Achterberg C., Horstmann K., 2005. World Ichneumonoidea 2004. Taxonomy, biology, morphology and distribution [Braconidae]. Taxapad 2005

(Scientific names for information management) Interactive electronical catalogue on DVD/CD-ROM. Vancouver.

Yu D. S., van Achterberg C., Horstmann K., 2016. Taxapad 2016, Ichneumonoidea 2015. Database on flash-drive. www.taxapad.com, Nepean, Ontario.

Zettel V. H., 1990. Eine Revision der Gattungen der Cheloninae (Hymenoptera, Braconidae) mit Beschreibungen neuer Gattungen und Arten. Annalen des Naturhistorischen Museums in Wien, 91(B), 147-196.

Zettel V. H., 2002. Pachychelonus maximus sp. n. (Hymenoptera: Braconidae: Cheloninae) aus Kenia. Linzer Biologische Beiträge, 34(1), 195-198. 